\title{
Factors affecting the deceased organ donation rate in the Chinese community: an audit of hospital medical records in Hong Kong
}

\author{
CY Cheung *, ML Pong, SF Au Yeung, KF Chau
}

This article was published on 24 Oct 2016 at www.hkmj.org.

\section{A B S T R A C T}

Introduction: The number of actual donors per million population is the most commonly used metric to measure organ donation rates worldwide. It is deemed inadequate, however, because it does not take into account the potential donor pool. The aim of this study was to determine the true potential for solid organ donation from deceased brain-dead donors and the reasons for non-donation from potential donors in the Chinese community.

Methods: Medical records of all hospital deaths between 1 January and 31 December 2014 at a large regional hospital in Hong Kong were reviewed. Those who were on mechanical ventilation with documented brain injury and aged $\leq 75$ years were classified as possible organ donors. The reasons why some potential organ donors did not become utilised organ donors were recorded and evaluated.

Results: Among 3659 patient deaths, 121 were classified as possible organ donors. The mean age of the possible organ donors was 59.4 years and $72.7 \%$ of them were male. The majority $(88 \%)$ were from non-intensive care units. Of the 121 possible organ donors, 108 were classified as potential organ donors after excluding 13 unlikely to fulfil brain death criteria. Finally 11 patients became actual organ donors with an overall conversion rate of $10 \%$. Reasons for non-donation included medical contra-indication (46\%), failure to identify and inform organ donation coordinators (14\%), failure of donor maintenance (11\%), brain death diagnosis not established (18\%), and refusal by relatives (11\%).

Conclusions: It is possible to increase the organ donation rate considerably by action at different stages of the donation process. Ongoing accurate audit of current practice is necessary.

\section{Hong Kong Med J 2016;22:570-5}

DOI: $10.12809 / \mathrm{hkmj} 164930$

${ }^{1}$ CY Cheung *, PhD, FHKAM (Medicine)

${ }^{2}$ ML Pong, BSc (Nursing)

${ }^{2}$ SF Au Yeung, BSc (Nursing)

${ }^{1}$ KF Chau, FRCP, FHKAM (Medicine)

1 Department of Medicine, Queen Elizabeth Hospital, Jordan, Hong Kong

2 Transplant Coordinating Service, Kowloon Central Cluster, Hospital

Authority, Hong Kong

* Corresponding author: simoncycheung@gmail.com

New knowledge added by this study

- There are different areas in the donation process where it may be possible to increase the organ donation rate considerably. Failure of health care professionals to identify potential donors is considered to be an important contributing factor to the shortage of cadaver organs in our community.

Implications for clinical practice or policy

All potential donors should be considered for referral to the intensive care unit for possible admission and physiological support through to brain death.

\section{Introduction}

Organ transplantation is considered to be the best treatment for patients having end-stage organ failure. There is a global shortage of organs, however. In the United States, more than 100000 potential recipients are waiting for organs of whom only one fourth will ultimately undergo organ transplantation. ${ }^{1}$ In a systematic medical review, Jansen et $\mathrm{al}^{2}$ showed that the maximum number of potential organ donors can be approximately 3 times higher than the number of effective organ donors. As a result, understanding the pitfalls at each step of the process of organ procurement, starting from donor identification to retrieval of organs, is extremely important in the evaluation of the size of the potential donor pool.

The number of actual donors per million population ( $\mathrm{pmp}$ ) is the most commonly used metric to measure organ donation rates and performances in different countries. It has been deemed inadequate, however, because it does not take into account the potential donor pool that is dependent on the rates and causes of death. Medical records review appears to be the most accurate method to estimate donor potential within a hospital or a region. ${ }^{3} \mathrm{~A}$ true estimate should reflect contemporary medical practice, donor identification, and consent rates; 
thus it can provide a useful tool for measuring organ procurement performance in a service area and highlight areas in the procurement system that can be improved.

Similar to other parts of the world, the shortage of organs for transplantation remains a challenge in Hong Kong. Organ transplants in Hong Kong, whether cadaver or living donations, are subject to regulation under the Human Organ Transplant Ordinance; the main purpose of which is to ensure that no commercial dealing is involved in organs for transplant. Currently over $90 \%$ of organ donations in Hong Kong are deceased donations, and the organ procurement system is based on an opt-in policy (voluntary decision of the patient or their family to donate organs). No executed prisoners are involved in the donation process. Although the deceased organ donation rate increased from 4.3 donors pmp in 2006 to $6.1 \mathrm{pmp}$ in 2013, Hong Kong continues to have one of the lowest donation rates among developed countries. ${ }^{4}$ Over 2000 patients were waiting for a solid-organ transplant in 2014 but only 112 deceased organs were utilised. ${ }^{5}$

In recent years, approximately $40 \%$ of deceased organ donation referrals in our territory came from intensive care units (ICUs) while the remainder came from non-ICU areas such as medical and neurosurgical wards. This is entirely different from other parts of the world where more than $90 \%$ of organ donation referrals come from the ICU. ${ }^{6}$ Most of the current data on organ donation potential were solely extracted from medical records in the ICU. ${ }^{2,7-9}$ The picture will be more complete, however, if we can also identify and include those patients who die in non-ICU wards but have the potential to become an organ donor if appropriate steps are taken. ${ }^{10}$ Nearly all studies on deceased organ donation have been performed in western countries and data are scarce for the Chinese population. The rates of donation will differ from one country to another because of differences in cultural, social, and historical factors; the organisational characteristics of the donation system; and various aspects of the health service.

We conducted a study to evaluate the deceased organ donation process at our centre using the critical pathway ${ }^{11}$ in order to identify to what extent and why potential brain-dead donors are missed. The main outcome measures included the potential organ donor suitability and the various reasons for non-donation as assessed by our organ donation coordinator (ODC). Different ways that could help to improve the organ donation process will also be discussed.

\section{Methods}

This was a retrospective study conducted at Queen Elizabeth Hospital, the largest regional acute hospital in Hong Kong with 1833 beds, serving

\section{根據醫院病歷紀錄探討影響中國社會遺體器官捐 贈率的因素 \\ 張志遠、龐美蘭、歐陽淑芬、周嘉歡}

引言：器官捐贈率是以每百萬人中捐贈者所佔的人數來計算, 這是全 世界衡量器官捐贈率最常用的指標。不過, 由於未有考慮到潛在器官 捐贈者, 這種方法仍有不足之處。本研究旨在找出華人社會中腦死亡 病人可以捐贈器官的真正潛在比率, 以及這些潛在器官捐贈者未有捐 出器官的原因。

方法：回顧2014年1月1日至12月31日期間香港一所大型分區醫院的 病歷紀錄。凡75歲或以下接受機械通氣並病歷紀錄顯示腦損傷的病人 均為潛在器官捐贈者。從紀錄中搜尋有關部分潛在器官捐贈者未能捐 贈器官的原因。

結果：研究期間共有 3659 人死亡，其中 121 人被列為可捐贈者。 他們平均年齡 59.4 歲， $72.7 \%$ 為男性；大部分（ $88 \%$ ) 來自非重症監 護病房。僘除 13 名不能界定為腦死亡的病人後, 108 人為潛在器官捐 贈者。最終有 11 人真正成為器官捐贈者, 總轉化率為 $10 \%$ 。末能捐 贈器官的原因有醫學禁忌症 $(46 \%)$ 、未能聯絡器官捐贈聯絡團隊 (14\%) 、捐贈器官維護失敗（11\%）、腦死亡診斷不成立 $(18 \%)$ 和 家屬拒絕捐贈（11\%）。

結論：在捐贈過程中可以透過不同行動大幅增加器官捐贈率。持續為 現時機制進行審核是必要的。

approximately $7.1 \%$ of our 7.2 million population. It is a tertiary referral centre of the major specialties including neurology and neurosurgery. In addition, it is one of the major organ procurement centres in our territory and contributed approximately 30\% of all deceased organ donors in 2014. All deceased donors in our centre are brain-dead donors as we do not have a donation after cardiac death policy.

Hospital medical records of all those who died at our centre (including both ICU and non-ICU areas) between 1 January and 31 December 2014 were reviewed by the same ODC. In case of ambiguous information, the opinion of another ODC at our centre was sought. Both ODCs had experience in managing patients with brain injuries and were knowledgeable about brain death. Clinical and demographic data including age, gender, cause of brain injury, Glasgow Coma Scale (GCS) score, medical co-morbidities, and likelihood of progression to brain death were extracted from the medical records. Only those who had been on mechanical ventilation with documented brain injuries and aged $\leq 75$ years were included in our analysis. In our hospital, patients could receive ventilator care (but no invasive arterial pressure monitoring) in general wards other than the 29-bed ICU because the number of critically ill patients requiring intensive care might exceed the number of beds available in ICU. Patients could also be too 

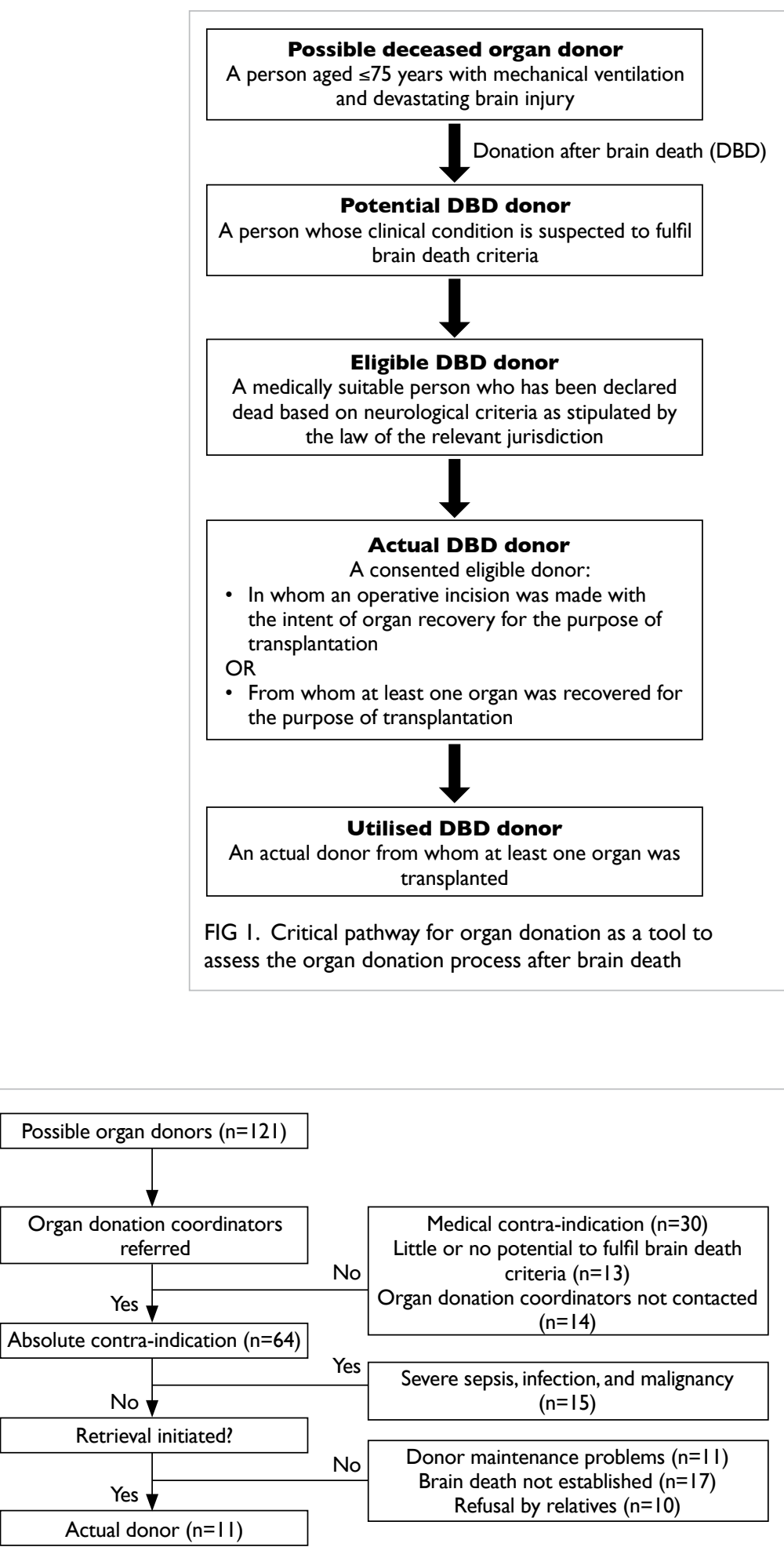

FIG 2. Breakdown of aggregated data of our medical record review

ill and not fulfil the ICU admission criteria. During ICU consultations, patients were triaged by ICU specialists with reference to a prioritisation model. ${ }^{12}$ Patients remaining in the general ward would be cared for by the treating teams.

The critical pathway for organ donation was used as a tool to assess the organ donation process after brain death. ${ }^{11}$ The various definitions of organ donors used in this study are shown in Figure 1. The 'Guidelines on diagnosis of brain death' were first prepared in 1995 with assistance from the Hong Kong Society of Critical Care Medicine. They were revised later and supported by the Hospital Authority (HA) of Hong Kong. ${ }^{13}$ Brain death is established by the documentation of irreversible coma and irreversible loss of brain stem reflex responses and respiratory centre function or by the demonstration of the cessation of intracranial blood flow. The recommendations for the status of the two medical practitioners certifying death are shown in the guideline. The concept that brain death is equivalent to death is accepted legally and within the medical community in Hong Kong.

Medical suitability for organ donation was based on our 'Guideline for evaluation and selection of potential organ/tissue donors' prepared by the HA. ${ }^{14}$ The likelihood of progression to brain death was based on the GCS score, presence or absence of brainstem reflexes, rapidity of deterioration, and findings of cerebral tomography. Potential braindead organ donors were defined as patients with the likelihood of progression to brain death. The various reasons why some potential organ donors did not become an organ donor were recorded and evaluated. The study was approved by our hospital ethics committee.

\section{Statistical analyses}

The Statistical Package for the Social Sciences (Windows version 21.0; SPSS Inc, Chicago [IL], US) was used to perform the statistical analyses. Continuous data were expressed as means \pm standard deviations or medians (ranges), and categorical data were expressed as percentages. Continuous data were analysed by Mann-Whitney $U$ tests to detect the difference between groups while categorical data were analysed by Chi squared test or Fisher's exact test. A P value of $<0.05$ was defined as statistically significant.

\section{Results}

There were a total of 3659 patient deaths during the study period. Among them, only 233 patients were put on mechanical ventilation with documented brain injury. On initial review, 112 patients were excluded due to old age ( $>75$ years). The remaining 121 possible organ donors were further analysed (Fig 2).

Among the 121 possible organ donors, only 14 (12\%) were from ICU. Most were from the non-ICU areas including 64 from neurosurgical wards and 43 from general medical wards. The mean age of our possible organ donors was $59.4 \pm 13.0$ years and 88 were male and 33 female. 
Of the 121 possible organ donors, 64 (52.9\%) were identified and referred to ODC for consideration of organ donation. Only eight (12.5\%) patients were from ICU and 56 (87.5\%) were from non-ICU areas. Among the 64 referred patients, 15 were medically unsuitable and 11 had maintenance problems related to haemodynamic instability. For the remaining 38 patients, brain death diagnosis could not be established or completed (did not fulfil all the criteria) in 17 . Hence only 21 patients (4 in ICU and 17 in non-ICU) finally became eligible organ donors after brain death. The relatives of all these eligible donors were approached by our ODC, 11 of them became actual organ donors ( 3 in ICU and 8 in non-ICU) and 10 patients did not proceed to organ donation because of refusal by patient relatives. The overall consent rate at our centre was $52 \%$ and the consent rate was higher in ICU than in the non-ICU areas although the difference was not statistically significant $(75 \%$ vs $47 \% ; \mathrm{P}=0.31)$. All actual organ donors finally became utilised organ donors. Of the 57 patients who had not been referred to ODC, 30 were medically unsuitable for organ donation after careful review of hospital records, 13 had little or no potential to progress to brain death, while the remaining 14 could have become potential organ donors if the ODC had been informed in a timely manner.

Among the 108 patients who were classified as potential brain-dead organ donors (after excluding 13 unlikely to fulfil brain death criteria), 13 patients were from ICU and 95 were from non-ICU areas. The baseline characteristics of these potential donors are shown in the Table. The potential donors in ICU were younger than those in non-ICU wards (although only marginally significant) and there was no significant difference in gender between the patients from ICU and non-ICU areas. More patients had traumatic brain injury and hypoxic brain damage in ICU and in non-ICU wards (neurosurgical or medical units) more patients had intracranial haemorrhage or ischaemic stroke. Only 11 of the 108 patients finally became actual organ donors with the overall conversion rate of $10 \%$. The conversion rate was higher in ICU than in non-ICU although it was not statistically significant (23\% vs $8 \% ; \mathrm{P}=0.10)$. The reasons for non-donation $(\mathrm{n}=97)$ included medical contra-indication $(n=45,46 \%)$, failure to identify and inform our ODC $(n=14,14 \%)$, failure of donor maintenance $(n=11,11 \%)$, brain death diagnosis not established or completed $(n=17$, $18 \%)$, and relative's refusal for organ donation $(n=10$, $11 \%)$. There was no significant difference between ICU and non-ICU areas concerning the reasons for non-donation $(\mathrm{P}=0.42)$.

\section{Discussion}

To our knowledge, this is the first comprehensive study to evaluate the pool of potential brain-dead organ donors in a large regional hospital in the Chinese community. Lack of consent to a donation request was the primary cause of the gap between the number of potential donors and the number of actual donors in the United States and United Kingdom. ${ }^{7,8}$ In order to tackle this problem, more resources should be invested to improve the process of obtaining consent. ${ }^{8}$ Good donor management including identification, evaluation, and donor

TABLE. Baseline characteristics of all potential deceased organ donors

\begin{tabular}{|c|c|c|c|}
\hline \multirow[t]{2}{*}{ Characteristic } & \multicolumn{2}{|c|}{ No. $(\%)$ of patients* } & \multirow[t]{2}{*}{$P$ value } \\
\hline & $\operatorname{ICU}(n=13)$ & Non-ICU (n=95) & \\
\hline Mean (range) age (years) & $51(2-73)$ & $62(23-75)$ & 0.05 \\
\hline Male & $7(54)$ & $71(75)$ & 0.18 \\
\hline Cause of brain injury & & & $<0.01$ \\
\hline Intracranial haemorrhage & $4(31)$ & $66(70)$ & \\
\hline Ischaemic stroke & $0(0)$ & $16(17)$ & \\
\hline Traumatic brain injury & $5(38)$ & $7(7)$ & \\
\hline Hypoxic brain damage & $4(31)$ & $6(6)$ & \\
\hline Utilised organ donors & $3(23)$ & $8(8)$ & 0.10 \\
\hline Reasons for non-donation & & & 0.42 \\
\hline Medical contra-indication & $5(50)$ & $40(46)$ & \\
\hline Failure to identify & $3(30)$ & $11(13)$ & \\
\hline Donor maintenance problems & $1(10)$ & $10(11)$ & \\
\hline Brain death diagnosis not confirmed & $0(0)$ & $17(20)$ & \\
\hline Relatives refused to donate & $1(10)$ & $9(10)$ & \\
\hline
\end{tabular}

Abbreviation: ICU = intensive care unit

* Unless otherwise indicated 
maintenance are also key factors in the successful recovery of organs in the donation process.

Failure of health care professionals to identify potential donors is considered an important contributing factor to the shortage of deceased organs, ${ }^{11,15}$ and accounted for $14 \%$ of our potential organ donor loss. Education directed at doctors and nurses to increase their awareness of possible organ donors is crucial to the success of an organ donation programme. Identification of a possible deceased organ donor should be inherently linked to the act of referral to a key donation person/team for activation of the deceased donation process. ${ }^{11}$ Similar to other hospitals in Hong Kong, all possible brain-dead donors at our centre, regardless of apparent medical contra-indications, are referred to our ODC as soon as they are identified. Referral usually occurs early when the clinical condition reveals death to be imminent or that further treatment will be futile. The possible deceased organ donors can then be assessed and managed by the ODC immediately as all the ODCs in our territory have a centralised shared 24-hour on-call system. The decision for medical suitability is made by our ODC and transplant physicians instead of referring teams because studies have shown that $11 \%$ of the decisions not to refer a potential donor based on medical grounds are incorrect. ${ }^{16}$ In our centre, only $52.9 \%$ of the possible deceased organ donors were identified and referred to our ODC. This figure was lower than some European countries (approximately $80 \%$ on average) such as $93.6 \%$ in France to $47.7 \%$ in Finland. ${ }^{9}$ One important unique feature in our study was that most of the potential deceased organ donors at our centre (also in Hong Kong) were identified in the non-ICU wards. This was in contrast to other countries where nearly all potential donors come from ICU., ${ }^{2,9}$ As a result, increased awareness of frontline staff and compulsory referral of all possible deceased organ donors may further increase the donation rate.

In our study, one third (27/87) of the nonutilised potential organ donors in the non-ICU areas were lost either because of a haemodynamically unstable condition leading to cardiac death or the failure to confirm or complete the brain death diagnosis. Brain death is often associated with marked physiological instability that makes it difficult to be managed in general wards by non-ICU specialists. In addition, due to the limited manpower and high hospital bed occupancy rates, most potential organ donors in general wards would no longer be supported for organ donation if brain death could not be confirmed within 72 hours. These patients might turn out to be eligible organ donors if they can continue to receive critical care management in ICU. Our study also showed that the consent rate was higher for potential donors from ICU than from non-ICU areas although it was not statistically significant. Some ICU specialists believe that all potential donors should be referred to ICU for possible admission and physiological support through to brain death. ${ }^{10}$ Additional resources, including ICU specialists and ICU beds, will be required however. As an alternative, a mobile team including ICU doctors and nurses could be set up, aiming to give advice for potential organ donor support and optimisation of settings towards brainstem tests in non-ICU wards.

As in many other countries, a high family refusal rate is a significant reason for potential donor losses in Hong Kong. In our study, the overall refusal rate was $48 \%$. This was higher than the family refusal rates in Spain (24.3\%), the United Kingdom (41\%), France and Belgium (10.5\% in both). ${ }^{7,9}$ There are numerous ethnic, cultural, social, and religious factors that contribute to disparities in deceased donation in different Asian countries. Since the Chinese community is deeply embedded with the traditional belief of preserving body integrity after death, most Chinese communities such as Hong Kong have adopted an opt-in system. ${ }^{16}$ The presumed consent or opt-out system is a controversial topic in our territory. It is uncertain whether the public would support presumed consent ${ }^{17}$ because it violates our conventional ethical and legal principle of familial authority over a deceased body. A survey in Hong Kong showed clear objection (66\%) to presumed consent for organ donation and only $28 \%$ agreed. ${ }^{18}$ Any health policies and educational campaigns to increase donation rates must contend with different cultural contexts and conceptions of autonomy to be effective. In November 2008, the Hong Kong SAR Government established the Centralised Organ Donation Register to make it more convenient for people to register their wish to donate organs after death. Media coverage of patients' appeals for organs and transplant success stories can draw public support and boost public confidence in organ transplantation. ${ }^{19}$

One of the drawbacks of our study was the small number of patients that might not provide sufficient power to detect the differences between potential donors from ICU and non-ICU areas. It is also difficult to compare our results exactly with other studies because of the variation in definition of a potential donor and the difficulty in predicting the likelihood of progression to brain death. Furthermore, as we only analysed those patients who were mechanically ventilated, some potential organ donors might still be missed as it is not our current practice to perform tracheal intubation and mechanical ventilation solely for the purposes of facilitating organ donation.

\section{Conclusions}

We have identified different areas in the donation 
process where it may be possible to increase the organ donation rate considerably. Among them, increasing awareness of frontline staff in identification of potential donors in both ICU and non-ICU areas, and appropriate physiological support of potential donors to accomplish the diagnosis of brain death in general wards are key elements in our hospital. Ongoing accurate audit of practice is a prerequisite to improve the organ donation process.

\section{Declaration}

All authors have disclosed no conflicts of interest.

\section{References}

1. OPTN (Organ Procurement and Transplantation Network). U. S. Department of Health and Human Services. Available from: http://optn.transplant.hrsa.gov. Accessed 1 Jun 2015.

2. Jansen NE, van Leiden HA, Haase-Kromwijk BJ, Hoitsma AJ. Organ donation performance in the Netherlands 200508; medical record review in 64 hospitals. Nephrol Dial Transplant 2010;25:1992-7.

3. Christiansen CL, Gortmaker SL, Williams JM, et al. A method for estimating solid organ donor potential by organ procurement region. Am J Public Health 1998;88:1645-50.

4. IRODaT (International Registry in Organ Donation and Transplantation). Transplant Procurement Management. Available from: http://www.irodat.org. Accessed 1 Jun 2015.

5. Department of Health, The Hong Kong SAR Government. Organ donation. Available from: http://www. organdonation.gov.hk/eng/statistics.html. Accessed 1 Jun 2015.

6. Mascia L, Mastromauro I, Viberti S, Vincenzi M, Zanello M. Management to optimize organ procurement in brain dead donors. Minerva Anestesiol 2009;75:125-33.

7. Barber K, Falvey S, Hamilton C, Collett D, Rudge C.
Potential for organ donation in the United Kingdom: audit of intensive care records. BMJ 2006;332:1124-7.

8. Sheehy E, Conrad SL, Brigham LE, et al. Estimating the number of potential organ donors in the United States. N Engl J Med 2003;349:667-74.

9. Roels L, Spaight C, Smits J, Cohen B. Donation patterns in four European countries: data from the donor action database. Transplantation 2008;86:1738-43.

10. Opdam HI, Silvester W. Identifying the potential organ donor: an audit of hospital deaths. Intensive Care Med 2004;30:1390-7.

11. Domínguez-Gil B, Delmonico FL, Shaheen FA, et al. The critical pathway for deceased donation: reportable uniformity in the approach to deceased donation. Transpl Int 2011;24:373-8.

12. Guidelines for intensive care unit admission, discharge, and triage. Task Force of the American College of Critical Care Medicine, Society of Critical Care Medicine. Crit Care Med 1999;27:633-8.

13. Hospital Authority Head Office Operations Circular No. 13 / 2010: Guidelines on diagnosis of brain death. Hong Kong: Hospital Authority; 2010.

14. Guideline for evaluation and selection of potential organ/ tissue donors (revised version). Hong Kong: Hospital Authority; 2016.

15. Boey KW. A cross-validation study of nurses' attitudes and commitment to organ donation in Hong Kong. Int J Nur Stud 2002;39:95-104.

16. Wu AM. Discussion of posthumous organ donation in Chinese families. Psychol Health Med 2008;13:48-54.

17. Wu AM, Tang CS. The negative impact of death anxiety on self-efficacy and willingness to donate organs among Chinese adults. Death Stud 2009;33:51-72.

18. Cheng B, Ho CP, Ho S, Wong A. An overview on attitudes towards organ donation in Hong Kong. Hong Kong J Nephrol 2005;2:77-81.

19. Lo CM. Deceased donation in Asia: challenges and opportunities. Liver Transpl 2012;18 Suppl 2:S5-7. 